\title{
1. Departure and roadmap, provisions and destiny
}

\subsection{ABIDE AT THE FRONTIER OF SOCIAL RESEARCH}

Sometimes words and concepts are either helpless or confusing when it comes to communicating phenomena. Instead, identification through our senses is immediate and convincing. Recognizing a human face is a wellknown example of such tacit knowing, and entrepreneurship as embodied in persons and their doings another. While entrepreneurship researchers have great difficulty in agreeing on a conclusive ostensive definition of entrepreneurship, ordinary people are often heard exclaiming: 'She is a typical entrepreneur!' Perception then appears as a more original way of confirming insight than conception, the original point of departure for most scientific inquiry. Scholars should take this inexplicable yet genuine insight to heart and look for ways of relating it to scientific findings. This is not always possible, since the two modes of knowing appear incompatible. Bourdieu (1990; chap. 5) is generally sceptical of scholars' ability to inquire into practices. However, rather than giving up altogether, researchers must reconsider their ways of approaching phenomena.

Tsoukas and Chia (2002: 571), referring to Bergson and Wittgenstein, argue that in order to genuinely understand social phenomena as scholars we have to 'bring ourselves in touch with reality through intuition; get to know it from within' (emphasis in original). Inspired by Heidegger, Chia states, along with Nayak (Nayak and Chia 2011), that researchers have to adopt a 'dwelling' mode of engagement that pays attention to what people do, in other words their practices. Weick (2003: 457) maintains that in order to really understand what practice is all about in such a context as scholars we have to accept being 'thrown' into the world, which creates a state of 'unknowability, unpredictability and enactment'. It seems that if we want to further our understanding of entrepreneurship we have to retreat from conventional research methods and rather associate with everyday sense-making, which builds common sense.

Traditionally, research is associated with accumulative knowledge building. This view may be valid in natural sciences, where it is reasonable 
to assume that there is one reality to investigate. In social sciences there are, however, many realities to study and, in addition, they all change and sometimes in a similar direction. Zygmunt Bauman argues that the contemporary world is 'liquid', meaning transient and fragmented, not the least because of the general digitalization and impact of social media.

Ours is ... an individualized, privatized version of modernity, with the burden of pattern-weaving and the responsibility of failure falling primarily on the individual's shoulders. It is the patterns of dependency and interaction whose turn to be liquefied has now come. They are all malleable to an extent unexperienced by, and unimaginable for, past generations, but like all fluids they do not keep their shape for long. Shaping them is easier than keeping them in shape. Solids are cast once and for all. Keeping fluids in shape requires a lot of attention, constant vigilance and perpetual effort - and even then the success of the effort is anything but a foregone conclusion. (Bauman 2000: 7-8)

Such a world confirms that only by adopting an ontology of becoming will it be possible to comprehend these processes in the contemporary 'era of instantaneity'. This is basically about staying curious about and alert to the world as it changes and recognizing it as mouldable, or 'enactable', a view that some entrepreneurship researchers such as Gartner (2016) have touched upon. Considering Bauman's statement, it is even more important to state that all humans possess this aptitude - as children. Wherever located in space, children in their everyday play instantaneously test upcoming ideas; in other words, they practise entrepreneurship as a way of life (Johannisson 2010). Just as children consider change as a natural state, Bauman (2000) argues, all humans and adults in contemporary times of 'light modernity' have to adopt a nomadic behaviour. This suggests that a quest for the distinct and generic features of entrepreneurship (cf. Moroz and Hindle 2011) should begin by recognizing it as a prosaic and processual phenomenon, addressing it as 'entrepreneuring' (Steyaert 2007; Hjorth et al. 2015; Verduyn 2015). This present participle format is also what I use from now on.

In his thorough review of process frameworks in the field of entrepreneurship, Steyaert (2007) considers alternative theories and methodologies. Some of these adopt a pragmatic perspective, but none of them explicitly associates with practice theory, which takes its point of departure in concrete actions and interactions. Lacking an appropriate conceptualization of entrepreneuring as practice, researchers in the field are content either with theorizing or with investigating entrepreneurial phenomena by means of conventional approaches. This may explain why the field of entrepreneurship research is still accused of being immature, even underdeveloped, with little hope of ever becoming a 'real' discipline. An effect but also an 
enforcing factor behind this unfortunate status is that high-quality entrepreneurship research is published in highly ranked management journals rather than in the field's own publications (Johannisson 2018). Breaking out of this vicious circle can only be accomplished by providing a robust paradigmatic platform that consistently brings together ontological, epistemological and methodological issues which can jointly make sense to entrepreneuring as practice. This is also where this book wants to make a contribution.

Weick (2003) provides a number of reasons why scientists and practitioners have difficulties in understanding each other. Several of these arguments relate to the unsettled dispute that social researchers, on one hand, should avoid getting personally involved in what they study and, on the other, must 'get under the skin' of the subjects. The first argument states that social researchers may contaminate the processed accounts if they do not systematically suppress their own personal interests, experiences, skills and feelings and, in addition, systematically scrutinize their findings with further possible biases in mind. Alvesson and Sköldberg's (2009) discourse on reflexive methodology as its climax provides a distinct rationale for structuring such measures. However, not all scholars agree on the possibilities and benefits of such a systematic scrutiny and argue instead, as indicated above, that only by becoming part of the social world of subjects will it be possible to understand it. One condition, however, is that the scholar engages in that world as a genuine, authentic human being. Håkan Törnebohm (1979), a Swedish scholar in the theory of science, accordingly argues that personal capabilities such as the researcher's own interest in the subject matter and appropriate skills should be considered productive in scientific research.

Expanding on this view, it may be suggested that researchers should become activists or free agents in a field that they master and use their scholarly and practical experience as a take-off point for active experimenting and systematic reflection in that context. Paul Feyerabend (1975) provokingly recommends free experimenting for gaining insight. Richard Swedberg (2014: 50-51) argues that keeping existing research at arm's length helps release the scholar's own creativity to the benefit of scientific progress. This is the challenge that I have accepted and, accordingly, I have proposed and developed a methodology that, addressed as 'enactive research', claims to make entrepreneuring as practice comprehensible and to disclose features that add to our knowledge about the phenomenon. Enactive research means that the scholar also adopts the identity of an entrepreneur and with such an amalgamated identity launches, organizes and finalizes a venture. Through the adoption of an auto-ethnographic method, conceptual elaborations on entrepreneuring as process and 
practice will be attainable. This is a response to the invitation by Hjorth et al. (2015: 603) to mobilize also the researcher's personal and intuitive capabilities to catch entrepreneuring.

It means we researchers acknowledge we are always already part of the world and that our writings and theories add to and change (if only a little). It is from within such participation that a kind of super-empiricism is realized, a sensitivity to events which themselves are underway and to which the researchers as well as the researched belong.

Accordingly, the enactive methodology is here ontologically and epistemologically founded and empirically illustrated in detail.

Enactive research is obviously a radical way of doing social research. Its emic, experience-based, 'dwelling' mode and associated performative definition of entrepreneurship are however needed to replace the etic, 'building' mode and ostensive definitions that still dominate entrepreneurship research (cf. Latour 1986; Feldman 2000; Chia and Holt 2006). Argyris and Schön (1974) argue that practitioners use personal theories to guide their actions. Accordingly, entrepreneurs may be asked about their theories-in-use which may be espoused in either a structured or a narrative format and used to conceptualize the key features of (successful) entrepreneurs. Sarasvathy $(2001,2008)$, for example, adopts a structured approach to identify alternative entrepreneurial logics - causation versus effectuation. Hytti (2003), Hjorth and Steyaert (2004) and Gartner (2007) provide alternative narrative approaches to entrepreneurship. Alternatively, the concrete behaviour of entrepreneurs may be taken as the point of departure. Carter et al. (1996) thus ask nascent entrepreneurs what activities they have carried out in their venturing process. Yet another option in order to track their doings is to 'shadow' entrepreneurs (Czarniawska 2007). However, in all these approaches the risk of biased statements and behaviours is high, since they may be made only to please the researcher or just because the subjects are under surveillance. Neither do spontaneously espoused reflections made by practising entrepreneurs on their doings as professionals propose a road forward. Such experiences, often addressed as 'just anecdotes', are usually validated by traditional scientific criteria, which erases their possible contributions to our insight. The only way to deal with the dilemma that neither the practitioners' or entrepreneurs' honesty nor the open-mindedness of the research community can be taken for granted is to make the scholars themselves engage as entrepreneurs. Obviously, enacted inquiries into entrepreneuring are much needed.

This text has four objectives. The first is to provide the paradigmatic foundations needed for developing a methodology that recognizes entrepreneuring as practice. This means that entrepreneuring materializes 
as patterns of doings and relatings that are situated in time and space. The adopted ontology of becoming proposes that the world wherein entrepreneurship abides appears unknowable and constantly moving. This means that the world is genuinely ambiguous, which on one hand entails that it provides no permanent structure to hang on to and, on the other, offers endless options for enactment. This has radical consequences for our understanding of entrepreneuring. Instead of being about triggering change in an overly institutionalized world, which is the understanding that historically has dominated the field, entrepreneuring appears as temporarily stemming change in a transient world and as a force whose agency originates in a sensitive dialogue between humans and situations that a liquid world incessantly produces.

The book's second objective is to present a methodology that can bridge researchers' attempts to provide explanations and practitioners' need to make their local world comprehensible. The ambition is thus to link explicit, formal and general knowledge on one hand and tacit, informal and situated knowledge on the other. The proposed 'enactive' approach means that the researcher coalesces that identity with that of a practitioner or entrepreneur. Researchers need to become agents and activists, acknowledging and mobilizing all their intellectual as well as embodied skills, cognitive as well as affective and conative ones. Only then will it be possible for them to capture entrepreneurship as a special kind of practice and to use that insight to provide a conceptualization of entrepreneuring that originates in practice itself. In addition, enactive researchers use their personal experiences from enacting ventures to create value other than economic, which is necessary for building a better world. Paraphrasing the text on the back cover of Spinosa et al.'s (1997) thought-provoking book, I argue that scholars, entrepreneurship researchers in particular, are at their best not when they are engaged just in abstract conceptualization but when they are intensely involved in changing taken-for-granted everyday research practices. Accordingly, I introduce the notion of 'entresearcher' to depict the composite role or identity of a researcher who also acts as an entrepreneur. 'Entre' as a prefix is associated with entering into the space between two arenas for knowledge creation - scholarship and practice where scholars appear as constant 'searchers' for further insights into entrepreneuring.

The third objective is to empirically demonstrate the practice of enactive research on two comprehensive and complementary enacted ventures and to organize the insights gained into a practice theory of entrepreneuring.

The book's fourth objective is to reflect upon the implications of the proposed methodology and of the associated revised understanding of entrepreneuring on key contemporary debates in the field, including the 
need for critical theorizing on entrepreneuring, and the call for reflections on moral issues, as well as on the implications of a practice perspective on entrepreneurship education and our image of the 'entrepreneurial' university. Finally I assert that our close company with entrepreneurs gives us the opportunity but also the responsibility to use our reborn curiosity and playfulness to vitalize the social sciences with new approaches and methodologies in the spirit of Feyerabend (1975), Law (2004) and Swedberg (2014). I even frankly argue that such originality in social research should be considered as a third quality criterion in addition to rigour and relevance.

\subsection{A CALL FOR AUTHENTICITY IN SOCIAL RESEARCH}

The proposed enactive approach engages the scholar not just as a professional but also as a person or human being. It therefore requires courage and persistence during the research process as well as responsibility for the effects both on those involved and on society of the venture that has been enacted. Obviously, enactive research assumes that imaginative thinking by scholars in the armchair and creative writing at the desk are seldom enough to change the world. Words become universal deeds only if uttered and communicated by somebody with a track record that includes demonstrating the ability to make a difference in several communities of practice. Besides, fiction in the form of imaginative literature and art is best at evoking ideas through writing about what entrepreneuring may be like. Mark Twain, for example, neatly demonstrates how Tom Sawyer turns the resignation when facing a boring painting assignment into an entrepreneurial initiative. The movie The Kid makes Charlie Chaplin and his adopted son an entrepreneurial team in the glazier business. Still, doing is more than reading and seeing. The practice turn does not just challenge the linguistic counterpart by proposing a different epistemology for writers on social phenomena. As manifested in enactive research, it also suggests that scholars have to engage personally to become able to trigger the embodied action that generates original insight and then also take responsibility for their own initiatives. Even in natural sciences researchers engage beyond their intellectual capabilities. The double Nobel laureate Marie Curie used her body when experimenting with radium in order to deepen her insights (Hemmungs Wirtén 2015). This unlimited commitment is to practise authenticity as a researcher.

In other forms of inquiry into the social world, personal involvement is institutionalized. In critical journalism and conceptual or performative 
art, embodied knowledge reflecting whole-hearted engagement is more often mobilized. Thus the German journalist Günther Wallraff appeared in disguise in different contexts to reveal how power was misused, for example in the way immigrant workers were actually treated by the large corporations. When he was rewarded in 1986 by a Swedish newspaper for his then recently published report 'Tief unten' I was in the audience at the prize ceremony. In his speech of thanks he mentioned a number of people who might be able to perform similar critical investigations, like politicians and employees. He did not refer, however, to researchers. I managed to waylay Wallraff when he was about to leave the event and asked him in my broken German why he did not include scholars among potentially critical participant investigators. He answered concisely: 'Die haben nicht Geduld genug' [They are not patient enough]. Since I was at the time reporting from an action-research project, his criticism did not hit me personally, but it obviously made me start reflecting on even more radical ways of doing social research.

Entrepreneurs and artists are assumed to share some features, not least those of being creative and challenging social norms. Compare Scherdin and Zander (2011). The comparison is especially relevant when it comes to conceptual and performative art, with the German artist Joseph Beuys as a prominent example. See also Hjorth and Holt's (2016) reflections on Ai Weiwei's art as entrepreneurial eventing. Lars Vilks is probably the internationally best-known Swedish conceptual artist. For decades he has used his creativity and energy to tease Swedish institutions, thereby practising what we address as 'extreme' or 'radical' entrepreneurship (Johannisson and Wigren 2006; Johannisson and Wigren-Kristoferson 2015). Thus, when Vilks was sued for building one of his huge sculptures on private land, he presented, in alliance with a publisher, his Arx sculpture in the form of a book made of concrete and stones. He then provided the different parts of the sculpture with 'page numbers' and sold the pages one by one to prospective customers. In this way he raised the money needed to pay the fines.

While still an art student, the Swedish performative artist Anna Odell enacted a suicide drama on a bridge in central Stockholm. Acting as if she was struck by acute depression, she made people passing by believe that she was going to jump from the bridge. Concerned pedestrians made an emergency call, and Odell was taken despite strong physical resistance to a mental hospital by the police and nursing personnel. When she eventually revealed her identity and real-life experiment she was criticized not only by the caring institutions involved but also by the general Swedish public. Finishing her education and continuing her career as an artist (including directing a movie, with herself playing the main part, on bullying that she herself had experienced at school), she has become recognized as an 
influential Swedish artist. In the autumn of 2015 she was honoured with a major exhibition at the Stockholm Cultural Centre. Anna Odell has certainly demonstrated how performative art can support conceptual art, in other words by "practices and debates that ... expose and criticize the basic social and political relations that bind art to society and culture' (Corris 2004: 12). While researchers are certainly expected to produce conceptualizations as part of their practice, the question I ask is if they are also able to accomplish 'performative research'. This would mean providing a methodology that is not only robust and relevant but also original by suggesting an alternative route to researching and conceptualizing, like here entrepreneuring.

Nothing, not even what is considered to be original and unique, is without its history. As a matter of fact, we live and learn by metaphors, analogy and comparison. The more the compared objects differ, the more we are triggered by imagination and the desire to connect what appear as contrasts. Every day I want to remind myself of that. Accordingly, my computer screen shows a beach on the western coast of New Zealand's South Island, which I and my wife visited in 1992. An enormously complex root system of a stranded tree dominates the picture. As located, the root divides water and land. On one side of the angled roots the picture shows the threatening yet promising ocean, while the other side depicts a forest that since its birth has as a collective of trees submitted politely to the wind from the ocean and adapted its shape to it. When I asked a colleague and friend of mine, who is also a gifted amateur photographer, about his opinion of the screen picture, he argued that it was unbalanced, almost confusing. I should have chosen either the ocean or the woods as a background. Authoring the present text I reflect that I am still attracted by the original image, since it represents both my understanding of entrepreneuring and the conditions for making it intelligible as a complex social process. The comment by my colleague reflects his professional expertise with respect to both photography and research. Traditional research calls for control over contingencies, especially when dynamic phenomena such as entrepreneuring are studied. To me the complex fabric of the root system of the tilted tree symbolizes the need for anarchic and rhizomatic images when forming a bridge between confirmed and streamlined theory (the wood) and wild and unbroken practice (the sea), two contrasting contexts for dealing with complex and dynamic phenomena such as entrepreneuring.

I think that the personal engagement that professionals like journalists and artists demonstrate is also needed in social research for the purpose of gaining insight and practising responsibility. In order to reveal the genuine features of entrepreneuring as practice, scholars have to immerse themselves in its concrete becoming by identifying with the entrepreneur, 
in other words do 'enactive research'. This means that scholars temporarily amalgamate their identity as researchers with their identity as entrepreneurs, launch a venture and live its emergence, from creation to closure, as an everyday becoming. Genuine involvement alone will make the combining of the two identities as researcher and entrepreneur into an authentic being as 'entresearcher'. In practice, this means that the positions as researcher and entrepreneur take turns, implying that scholars before and after the venturing process adopt the outsider's perspective, while during the venturing process being as insiders totally devoted to its concrete becoming.

Behind the 'enacting' label hides a challenging contradiction. On one hand, it means decreeing or creating a legal institution, the most definitively formal social structure that is democratically negotiated. It represents (formal) institutionalization in its glory (cf. Scott 2001). On the other hand, to Karl Weick ([1969] 1979), enactment is a product of coincidence and human imagination, a view that was adopted in entrepreneurship research by Gartner (2016). My view of enactment relates to both these views. In an ambiguous environment anything can be enacted, but the practising researcher takes responsibility for what she/he has enacted and does not desert it even if better options appear. Exactly as the notion of 'entresearcher' amalgamates the identities of researcher and entrepreneur, the moral and instrumental dimensions of enactment thus combine in enactive research. Reflecting on the consequences of enactments during and after the venturing process is as important as the conceptual and substantive outcomes of the enactment itself. Just as carefully as entresearchers design their reporting from their venturing process as scholars, they organize their entrance and exit as activists from the realities they themselves have deliberately created. Entresearchers have to be authentic and trustworthy, both as scholars and as practitioners and activists.

\subsection{ENTREPRENEURING AS PRACTICE AND THE PRACTICE OF ENACTIVE RESEARCH}

The rise of the practice perspective on social phenomena is different from other paradigm shifts. Usually such radical, Kuhnian dramas originate in and remain within the academic community. The core task for challenging paradigms is to outmanoeuvre existing conceptual frameworks and then demonstrate sustainability. The 'practice turn' confesses that there is a need to approach phenomena from the perspective of those who enact them. Still, what is surprising is that, in spite of this paradigmatic shift, the ways of approaching practices as empirical phenomena or adopted 
methodologies have not changed very much. Thus when, for example, Schatzki (2002) studies organizations, he relies on archival data, while Feldman (2000) adopts a set of quite conventional methods for making her case concerning practices. Neither of them seems to be greatly concerned that academic and practical work are guided by different epistemologies.

While the practice turn has been on the move for about two decades, it has taken scholars in entrepreneurship more than a quarter of a century to take up the clue that Peter Drucker offered with his seminal work Innovation and Entrepreneurship (1985). There may be several reasons for the late response to Drucker's challenging view. First, he himself brushed aside other understandings than the practice of entrepreneurship, referring to science and art. As an eminent writer on management, Drucker was widely read but not highly criticized and, if he was, it was more because of his perspective on entrepreneurship as a phenomenon than because of his methodology (Spinosa et al. 1997). Second, being annoyed by politicians and journalists preferring to listen to war stories by entrepreneurs rather than to ambitious scientific investigations, researchers probably think that they had better leave the practical perspective on entrepreneurship to practitioners. Third, when Drucker presented his book, entrepreneurship was new as a field of research. It was then more important to obtain legitimacy, which could be achieved by adopting established methodologies, than to try out new ways of investigating entrepreneurial phenomena. Fourth, only in the last decade or so has the interplay between research and external stakeholders been seriously discussed in the context of 'the entrepreneurial university'. As it is now about time to offer alternative modes of studying entrepreneuring as practice, enactive research is presented here as an option.

Searching for existing methodologies that can be related to enactive research is a project that is not very rewarding. Different interactive approaches such as Van de Ven's (2007) Engaged Scholarship do not provide any path-breaking methodology. In addition, they keep researchers and practitioners separated and the latter are only invited to negotiate the outcome of the knowledge-creating process. Then it may be more effective to consider other approaches that appear as contrasting but still adopt a similar logic. Enactive research is an inductive approach, and so is 'abduction', according to Charles Sanders Peirce, the pragmatist. Research based on abductive reasoning means carrying out an investigation which shows that a 'fact' that is considered to be an anomaly, being abnormal, becomes fully comprehensible. Enactive research into entrepreneuring is rather about showing that what does not yet exist, because it is considered to be impossible, can be made to materialize as a 'fact', even if today it is usually transient. 
Like any human activity, scientific research is a practice. Scholarly work includes a systematic variety of doings, including that which we more ceremonially address as methods and techniques, which jointly constitute the adopted overarching 'methodology'. More prosaically, methodology concerns how the scholar goes about conducting the inquiry, what concrete actions are taken, how previous research is taken into account and how empirical findings are considered. Often metaphors that relate to a concrete activity are used to explicate methodology. Morgan (1980) thus refers to it as 'puzzle solving', while Denzin and Lincoln (1994) compare qualitative methodology to 'bricolage', which means bringing together in a street-smart way different known methods and techniques for identifying and interpreting the phenomenon concerned. As with any production process, doing research includes designing, creating and connecting parts ('facts'), controlling quality and delivering findings to the scientific community. There are thus good reasons for treating research and the adopted methodology as 'just' another kind of practice. As with any practice, the appropriate methodology varies with the task and its context.

Enactive research into entrepreneuring thus means that entrepreneuring is studied on the same terms as it is being practised. When it comes to the enactment of the venture, the methodology treats the researcher and subjects equally. Once the identities as researcher and entrepreneur have amalgamated into that of an 'entresearcher', further subjects are invited as co-creators of the enacted venture. In the ambiguous world recognized by an ontology of becoming, the venture emerges out of a dialogue between those engaged in the enactment and the situations that an incessantly changing environment generates. This makes the practice of entrepreneuring and that of (enactive) research coalesce and able to produce both new insights into entrepreneuring as practice and further substantive value, depending on the aim of the enactive venture. By connecting philosophical ideas about a transient world with everyday practices, enactive research offers a methodology that deepens our understanding of entrepreneuring as creative organizing, whether in everyday (Steyaert 2004), organizational (Hjorth 2012) or societal (Berglund et al. 2012) settings.

\subsection{OUTLINE OF THE BOOK}

Chapter 2 opens by taking a standpoint on the controversial issue of whether social researchers can or even should distinguish between 'objective facts' and accounts that are coloured by personal attitudes and values. My argument is that such a separation is not possible, even if the systematic reflexivity procedure proposed by Alvesson and Sköldberg 
(2009) is followed. Instead, the scholar's personal interests and skills are to be mobilized in order to make enacted approaches to entrepreneuring as practice fruitful. Social constructionism, further supported by process philosophy, provides a basic understanding of a becoming world and rationalizes 'entrepreneuring' (Steyaert 2007) rather than 'entrepreneurship' as the proper signification of the phenomenon. Pragmatism and existentialism/phenomenology, including recognizing affection and conation as basic human faculties, supplement the traditional focus of social constructionism on forces that hamper agency. This is needed to approach entrepreneuring as both an existential and an instrumental endeavour.

Considering entrepreneuring as a relational and collective phenomenon, personal networking is presented as a generic mode of relating when orchestrating the entrepreneurial process as creative organizing. In entrepreneurs' personal networks, exchange of practical knowing dominates. Aristotle's three forms of knowledge - episteme and techne as intellectual knowing to be generalized and phronesis as embodied knowing for local use - present alternative modes of making the world comprehensible. In entrepreneurship research, phronesis has to be complemented by métis or 'cunning intelligence' (Letiche and Statler 2005; Johannisson 2014a, 2014b). Mētis and phronesis as practical knowing guide entrepreneurs instrumentally and morally in dealing with situated challenges (cf. Joas 1996). These epistemological statements provide the basis for proposing practice theory as an appropriate conceptual framework for inquiries into entrepreneuring. Inspired by, but also critically reviewing, Schatzki's (2002) image of practice theory and also consulting further practice approaches in organization studies, the proposed basic features of entrepreneuring as practice are outlined. The emergence of the entrepreneurial process then appears as a weaving process where the entrepreneur's experience envelops the ties of the personal network that make the warp, while the weft is constituted by the actions taken to deal with upcoming situations.

Chapter 3 on enactive methodology opens by generally commenting on the two distinctive key features of enactive research on entrepreneuring: the personal and practical engagement of the scholar and the enactment of a venture as an interactive process. Since neither of these issues has so far been studied empirically to any great extent, they have to be thoroughly discussed in the perspective of their foundations as presented in Chapter 2. In order to position the enactive approach, it is first compared with other ways of doing interactive research. One of the unique features of enactive research into entrepreneuring is the researcher's personal involvement in the concrete enactment of ventures, which puts the searchlight on the contrasting epistemologies adopted by scholars and practitioners. Keeping these differences in mind, a rationale consisting of eight steps for doing 
enactive research on entrepreneuring, or practising as an 'entresearcher', is presented.

The entresearcher's engagement varies qualitatively over the five phases of enactive field research: 1) preparation, 2) initiation, 3) actualization, 4) separation and 5) reflection. Phases two and three refer to the concrete enactment of the venture, while in phase 5 scholarly lessons are made inductively. The first phase entails the researcher's familiarization with the domain and empirical context, while the fourth concerns separation from the venture in orderly and responsible ways by 'hanging around' in the empirical context for some time after the closing of the venture. These integration and separation phases are needed in order to secure that the ambition of enactive research into entrepreneuring to also produce new value in society is being met. Auto-ethnography is the generic method used to organize the field research as a source of new insights into entrepreneuring as practice. Drawing on Van Maanen (2011), the overarching enactive approach is seen as a 'confessional tale' provided by the entresearcher. This tale embeds, first, a realist tale that chronologically describes the course of events. The main reporting from the field in terms of situated practices appears in the form of a collection of impressionistic, dramatized incidents aiming at reflecting the instantaneousness and concreteness of the situated entrepreneurial eventing. The chapter closes with a presentation and discussion of alternative criteria for evaluating enactive research.

Chapter 4 reports in detail from the two enacted events, the Anamorphosis and SORIS projects, the first of which materialized in 1999 and the second in 2014. The design of enactive research as presented in Chapter 3 was then applied slightly differently in the cases for two main reasons: first, because of the structural differences between the two projects and, second, because of the learning that took place in going from the first to the second project. In several respects, these projects, each lasting for about one year, are also comparable. Shared features include that the enactment took place at the interface between the university and the regional society, that students were involved, and that the ambition was to contribute with cultural and/or social, rather than economic, value to society. Major differences between the Anamorphosis and SORIS cases include a more structured enactment process and a much greater enrolment of students in the latter, which also organized three parallel ventures and was not a holistic one as in the Anamorphosis case. The brief realist tales of the Anamorphosis and SORIS projects are thus complemented by an extensive systematic comparison of the two cases along different structural dimensions, including not only the venturing processes per se but also their contexts and my own identity work as the entresearcher. Rich impressionistic accounts are provided in a 'vignette' format containing information about the 
'micro-dramas' that depict the emergence of situated practices in the two projects. These dramas thus indicate concrete ways of handling the varying 'situations' that emergent ventures have to cope with. Some of these challenges appear as 'circumstances' that have to be dealt with immediately, some concern 'predicaments' that may develop into emergencies, while some challenges are deliberately instigated by the entresearcher as experiments in order to test alternative ways of enacting or energizing the overall enactment process. The temporal embedding of the enacted activities by the preparations before and the follow-up after the closure of the ventures is also reported in order to show how these become integrated as concrete enactments into the regional setting.

Chapter 5 presents the contributions of the field research to a further conceptualization of entrepreneuring as practice. First, the basic conditions for and principles of the proposed enactive approach are summarized, involving that the world is liquid and the environment ambiguous, that enactive scholarship takes place by immersing oneself into the identity of an entresearcher, and that the venture is a collective effort orchestrated by the entresearcher through the personal network, the call for the entresearcher's ability to master two epistemologies and the need for an auto-ethnographic approach. I then elaborate on the weaving of a rag-rug, introduced in Chapter 2 as a generic metaphor for the entrepreneurial career. The friendship ties that constitute the personal network make, as enveloped by the entrepreneur's 'formative dispositions', the warp. These dispositions are identified in the field research and include: considering change and experimenting as a natural state; experiencing the personal network as a bodily extension; recognizing venturing as a collaborative undertaking; rationalizing and imputing agency to one's own actions across random events; safeguarding room for manoeuvring; and regarding institutions as competitors, indifference as an enemy and resistance as an energizer.

The weft that constitutes the rag-rug materializes as a bricolage of resources and the services that they contain. Some resources maintain the mundane everyday activity in the entrepreneurial process, while the spectacular and intense ones are mobilized when a new venture is to be enacted. The weaving process itself emerges as a stream of situated practices generated out of the dialogue between a dedicated entrepreneur and an unruly world. These situated practices appear as routinized improvisations generated by analogous reasoning based on the entrepreneur's own experience supplemented by that of the members of the personal network. Each entrepreneurial career has its own rhythm but is generally monitored by conscientiousness and grit as a duality. This implies that the entrepreneurial career is pursued by a simultaneous concern for details ('conscientiousness') and perseverance ('grit'). 
Chapter 6 brings up a number of issues that further integrate the analytical and empirical discourses provided in the previous chapters. Rather than critically questioning entrepreneurship as (nothing but) an economic phenomenon, enactive research concerns itself with entrepreneuring as the acknowledgement of general human capabilities and responsibilities for multiple value creation. The focus is thus on the potentially 'constructive' substantive contributions of the enacted ventures to society. Section 6.2 also brings up more general ethical concerns about the scholars' active involvement in the venture ('reality') creation process. The entresearcher's dominance - but also responsibility - is justified since in enactive research instrumental rationality is needed to accomplish value rationality. In Section 6.3 enactive research is positioned in the contemporary debate on 'the entrepreneurial university'. Being entrepreneurial is in this context usually associated with providing influential stakeholders, mainly the business community, with knowledge that serves their interests. Enactive research instead focuses on integrating a university's three missions research, education and outreach activities - in a way that also benefits the students and knowledge creation in the interest of society at large. Enactive research offers a road to conscientizing students about how values and practices may be colonized by powerful actors, and it bridges the epistemologies used by the academic and other communities of practice. Accordingly 'enactive research' is presented as a cornerstone in the entrepreneurial university. Finally, in section 6.4, I advocate the ability of enactive research to bridge formal, explicit knowledge, on one hand, and informal, tacit knowing, on the other, as a third criterion of high-quality research in addition to rigour and relevance. Social research in a world that has become increasingly liquid calls for new, original methodologies that are ontologically and epistemologically properly founded. 